\title{
Radiotherapy May Offer a Recurrence and Survival Benefit in Rectal Cancers Treated Surgically with Transanal Endoscopic Microsurgery: A Systematic Review and Meta-analysis
}

\author{
MICHAIL SIDERIS ${ }^{1}$, ANA NORA DONALDSON ${ }^{2}$, JOHN HANRAHAN ${ }^{3}$, \\ MATTHEW GRUNWALD ${ }^{4}$ and SAVVAS PAPAGRIGORIADIS ${ }^{5}$ \\ ${ }^{1}$ Women's Health Research Unit, Queen Mary University of London, London, U.K.; \\ ${ }^{2}$ Department of Applied Mathematics and Statistics, Stony Brook University, New York, NY, U.S.A.; \\ ${ }^{3}$ Faculty of Life Sciences and Medicine, King's College London, London, U.K.; \\ ${ }^{4}$ Department of Internal Medicine, SUNY Downstate Medical Centre, New York, U.S.A.; \\ ${ }^{5}$ International Society of Pelvic Surgery, Athens, Greece
}

\begin{abstract}
Background/Aim: Several studies report outcomes of Transanal Endoscopic Microsurgery (TEMS) surgery in combination with radiotherapy, however the combination of those treatments is provided mostly on an adhoc individual basis and the role of radiotherapy remains unclear. The aim of this study was to identify the effect of neo-adjuvant or adjuvant radiotherapy in the oncological outcomes of rectal cancer treated surgically with TEMS. Materials and Methods: We performed a systematic review of the literature on MEDLINE and Pubmed databases. Data were extracted by two independent reviewers and metaanalyzed using an inverse variance heterogeneity model to calculate overall (pooled) effect sizes for survival or recurrence of disease against neo+/-adjuvant treatment. Results: A total of 48 studies were included in the qualitative meta-analysis which included 3,285 patients with rectal cancer. The overall survival odds ratio $(O R)$, was 9.39 (95\% CI=6.1-14.4) with a Cochran's $Q$ variable of 151.7 on 47 degrees of freedom (d.f.) $(p=0.000)$. Recurrence-free OR was 8.7 (95\%CI=6.58-11.44) with a Cochran's $Q$ variable of $Q=145.2$ on 44 d.f. $(p=0.000)$. Studies which contained more than $10 \%$ of pT3 tumours,
\end{abstract}

This article is freely accessible online.

Correspondence to: Mr. Savvas Papagrigoriadis, International Society of Pelvic Surgery, Athens, Greece. Tel: +44 2032999000, e-mail: admin@societyofpelvicsurgery.org

Key Words: Radiotherapy, transanal endoscopic microsurgery, survival, local recurrence, rectal cancer, review. and provided neo+/-adjuvant treatment in more than $35 \%$ of cases, were associated with survival benefit, as demonstrated by an overall odds of survival of 32.2 (95\%CI=16.3-63.5, $p=0.001, Q=8.4, p=0.21)$. Studies that contained more than $10 \%$ of pT3 tumours and provided neo+/-adjuvant treatment in more than $20 \%$ of the cases had an overall effect size of recurrence-free odds of 20.23 (95\%CI=13.84-29.57, $\quad p=0.000, \quad Q=2.18, \quad p=0.54$ ). Conclusion: There seems to be a benefit from radiotherapy on overall survival and recurrence-free odds, which is more apparent in cohorts with more than 10\% of pT3 tumours. Our results suggest that neo-adjuvant or adjuvant radiotherapy should be considered for inclusion in formal treatment protocols for rectal cancers treated with TEMS as they offer a recurrence and survival benefit.

The surgical treatment of rectal cancer has been marked since the 1990s when the concept of Total Mesorectal Excision (TME) was introduced by Heald (1) and subsequently accepted by all Colorectal surgeons as the gold standard of surgery (2). The principle of TME is the complete removal of all regional lymph nodes en-block with the Mesorectal fascia and the rectum, regardless of whether an open or laparoscopic surgery is performed.

Around the same time as TME another surgical technique for rectal tumours was introduced by Buess (3). That was the Transanal Endoscopic Microsurgery (TEMS), a minimally invasive surgery performed with the aid of an operating endoscope and laparoscopic instruments (4). TEMS was initially introduced for benign rectal tumours offering the advantages of better technical excision and completeness in relation to the older Transanal Resection 
technique (TAR). TEMS required general anesthetic but no abdominal incision and could be performed as day surgery with minimal morbidity and mortality (4). It was the minimally-invasive nature of TEMS which tempted the first pioneers $(3,5)$ to attempt it as surgical treatment for early cancers, T1N0M0, on selected patients who were too high risk for TME because of comorbidities. On those selected patients TEMS was reported to have good results with survival equal to TME although local recurrence seems to be higher (6). Enthusiasts like the Italian team of Lezoche (7) performed and reported the first randomized trials of TEMS vs. TME for tumours of T1-T3 stages with negative nodes and neo-adjuvant radio-chemotherapy (7). The results were so good that a new wave of research has evolved over the last 10 years (4) which has eventually made TEMS, and other forms of endoscopic local excision, a legitimate treatment option for selected early tumours regardless of the patient operative risk. TEMS is recommended as an option now in many official guidelines such as those of NICE in the UK (8).

The issue of recurrence remains the main concern which has not allowed, so far, the wider application of TEMS in many rectal cancer cases. Recurrence is known to relate to several factors, the most important of which is tumour stage. It is widely accepted that TEMS is suitable only for cancers without positive lymph nodes, i.e. N0 of the TNM classification. It has also been shown that T3 tumours treated with local excision have an unacceptably high recurrence rate of around $50 \%$. T1N0M0 tumours are currently the main indication with a reported recurrence rate varying from 5 to $12 \%$. T2N0M0 tumours are also confined within the rectal wall and are candidates for TEMS according to the ESMO guidelines. The issue of histology, i.e. whether there are adverse histological features, as well as the fitness and perioperative risk of the patient are the other factors taken into account.

Adjuvant or neo-adjuvant radiotherapy with or without the addition of chemotherapy have been reported in this context, with variable results. There are no current guidelines recommending radio-chemotherapy for T1-T2 node-negative rectal tumours. However, it is obvious from the literature, as well as from the authors' own experience that those treatments are often added by multi-disciplinary teams to TEMS surgery when there is concern that surgery alone is not adequate. There is lack of systematic protocols of treatment and this is in contrast with the surgical treatment of rectal cancer with Total Mesorectal Excision where there are detailed protocols of treatment combinations.

The aim of our study was to investigate the effect of radiotherapy, adjuvant or neo-adjuvant, in the treatment of rectal cancers treated with TEMS surgery.

\section{Methods}

We searched Pubmed and Medline databases (January 1966-January 2016). We used the following MeSH subheadings "Transanal endoscopic microsurgery" (Medical subject heading [MeSH]), "TEM" (MeSH), and "TEMS" (MeSH) were combined with "rectal neoplasms" (MeSH), "rectal cancer" (MeSH), and "carcinoma of the rectum" (MeSH). In addition, we searched manually through the reference list from the retrieved papers for additional data. We have not included any published conferences extracts or any other nonpeer reviewed manuscripts.

Inclusion criteria. We structured our systematic review based on a "Population, Intervention, Comparison, Outcome" strategy. The population included patients who underwent TEMS with both curative or palliative intention for treatment of rectal tumours. That includes both prospective and retrospective observational studies, randomised-controlled trials, case-controlled studies and case-series. More specifically, we included any of the above studies that described at least one of the following primary outcome measures: survival and or overall recurrence of disease (local or distant). Only studies reporting cancers (and not just benign tumours) were included.

We compared our primary outcomes against neoadjuvant +/adjuvant radiotherapy treatment.

Exclusion criteria. Exclusion criteria included studies not published in English, studies that performed TEMS in less than five rectal cancer cases, studies that had no clear distinction between radical surgery and TEMs (mixed series) and studies that included benign rectal tumours. Reviewers examined all studies and excluded duplicate cohorts $(7,9,10)$.

Data extraction. Two independent reviewers selected the studies from the literature search. Data were extracted by both reviewers, and any conflict was resolved by the senior author. A PRISMA flowchart was constructed to map out the selection of studies (Figure 1).

Available Data. Study data were available on median age, sex, pT stage as well as operative time (minutes) and hospital stay (days). We also extracted the number of patients who received either neoadjuvant or adjuvant chemo+/-radiotherapy, and those who had completion surgery. The outcome variables that we based our analysis were cancer-related deaths, local recurrence and the need for salvage surgery. The effect sizes were therefore expressed in terms of odds of survival or odds of recurrence.

Statistical analysis. The principal analysis consists of meta-analysis and meta-analytic regressions to evaluate the significance of neo+/adjuvant radiotherapy treatment on the survival and overall recurrence. These meta-analytic algorithms provided valid aggregated (pooled) overall effect sizes for survival or recurrence odds ratios (OR) or log-odds ratio We assessed the significance of any heterogeneity between the effect sizes of the different studies, using Cochran's Q Statistic. The distribution was approximated by a Chi-square distribution with k-1 degrees of freedom (d.f.), where $\mathrm{k}$ was the number of studies. In the presence of heterogeneity, we selected a meta-analytic algorithm called "inverse variance heterogeneity" model (IV-Het) $(11,12)$ which controls for the between-region heterogeneity as the "random-effects algorithm" but, 


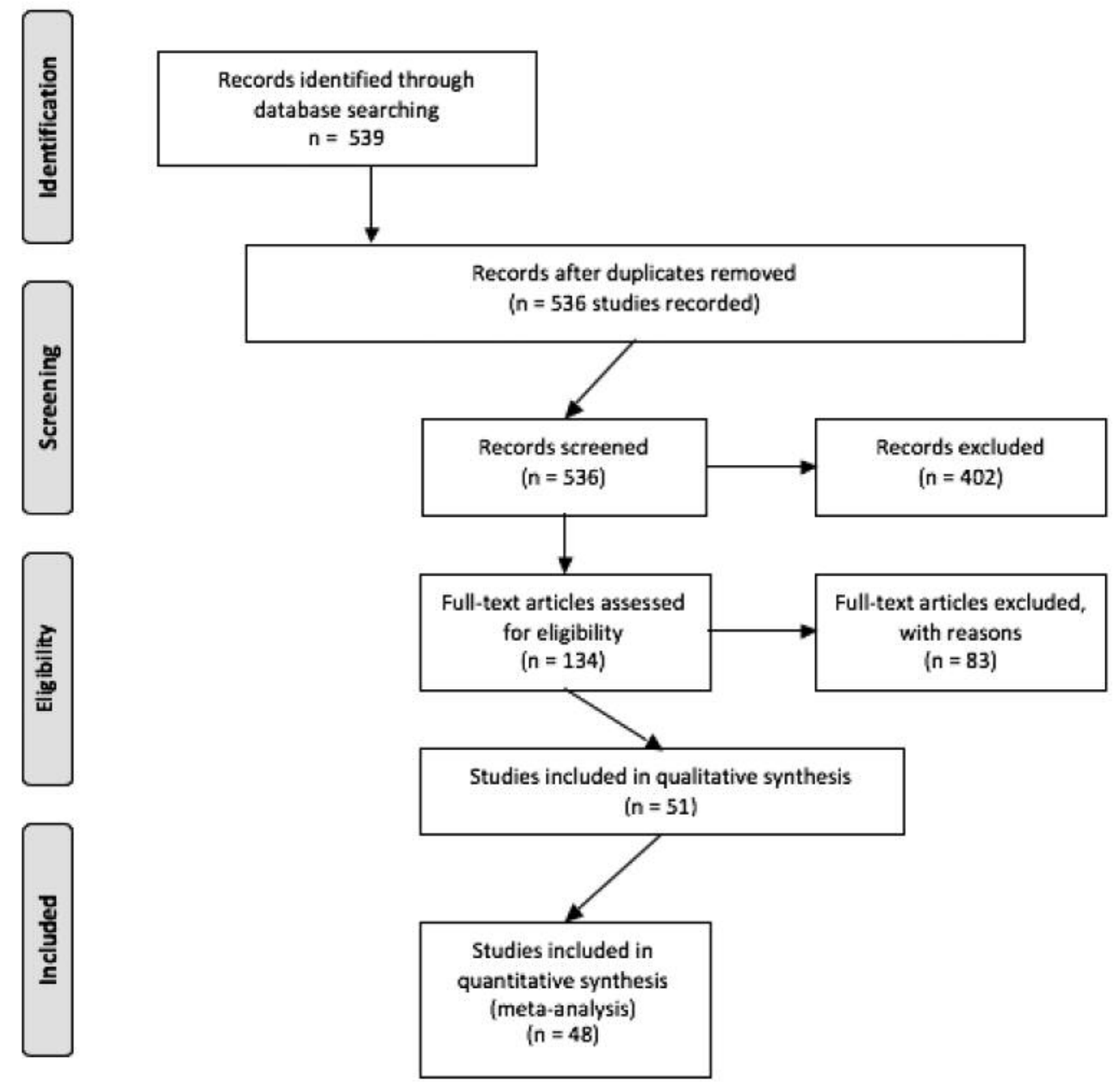

Figure 1. PRISMA flow chart.

additionally it gives more weight to those regions with larger sample size and less variability using inverse variance weights.

\section{Results}

A total of 51 studies were included in the qualitative synthesis and 48 were meta-analyzed (Table I) following exclusion of duplicate cohorts $(4,7,9)$. Those studies reported the results of 3,285 patients treated with TEMS plus or minus Radiotherapy. Overall survival is summarized on the relevant forest plot (Figure 2). Thirty-five out of 48 studies (72.9\%) used radiotherapy on a total of 1,069 patients $(32.5 \%)$. Of those patients 952 (89\%) received neo-adjuvant radiotherapy and the remaining 177 (11\%) received adjuvant radiotherapy. Only 14 out of 48 studies reported chemotherapy and the total number of patients who received chemotherapy was only 115 out of $3,285(3.5 \%)$. Considering the above numbers, the effect of chemotherapy was not possible to calculate independently and the effects of both adjuvant and neoadjuvant radiotherapy were pooled together in the analysis.

\section{Outcome: Overall Recurrence of disease}

Overall effect size. Recurrence-free odds ratios were between 0 and 0.31 . Table II and Figure 3 demonstrate the confidence intervals (CI) for the recurrence-free OR of all the 45 studies included in the final analysis, together with the weights assigned by the meta-analytic method. The overall effect size expressed in log-OR for recurrence-free was 2.16 (95\% CI $=1.89-2.44 ; \quad p=0.000)$ which was statistically significant (Figure 4). This is translated into an OR of recurrence-free of $8.7(95 \% \mathrm{CI}=6.58-11.44)$. We detected a highly significant heterogeneity and the Cochran's Q Statistic variable was $Q=145.2$ on 44 d.f. $(p=0.000)$. The variation in the log-odds-survival was attributed to heterogeneity and the I-sq statistic was $69.8 \%$. 
Table I. Effect sizes, confidence intervals and weights of each study.

\begin{tabular}{|c|c|c|c|c|c|}
\hline \multicolumn{2}{|c|}{ Study } & \multirow{2}{*}{$\frac{\mathrm{OR}}{7.89}$} & \multirow{2}{*}{$\begin{array}{c}\text { LCI } 95 \% \\
4.01\end{array}$} & \multirow{2}{*}{$\frac{\text { HCI } 95 \%}{16}$} & \multirow{2}{*}{$\frac{\text { Weight }(\%)}{5.20}$} \\
\hline 1 & Allaix (30) & & & & \\
\hline 2 & Araki (31) & 30.00 & 14.30 & 3699 & 0.31 \\
\hline 3 & Arezzo (32) & 28.00 & 1.67 & 469 & 0.30 \\
\hline 4 & Azimuddin (33) & 46.00 & 2.79 & 757 & 0.30 \\
\hline 5 & Baatrup (34) & 6.15 & 3.85 & 10 & 10.91 \\
\hline 6 & Bačić (35) & 6.56 & 3.31 & 13 & 5.08 \\
\hline 7 & Bretagnol (36) & 6 & 3 & 14 & 3.99 \\
\hline 8 & Caricato (37) & 10 & 1 & 181 & 0.28 \\
\hline 9 & Dafnis (38) & 24 & 1 & 405 & 0.30 \\
\hline 10 & De Graaf (39) & 75 & 15 & 378 & 0.91 \\
\hline 11 & DeMartines (40) & 11 & 2 & 60 & 0.82 \\
\hline 12 & Endreseth (41) & 7 & 2 & 25 & 1.31 \\
\hline 13 & Farmer (42) & 13 & 2 & 70 & 0.84 \\
\hline 14 & Flexer (43) & 84 & 5 & 1365 & 0.31 \\
\hline 15 & Floyd (44) & 106 & 7 & 1717 & 0.31 \\
\hline 16 & Ganai (45) & 14 & 5 & 41 & 2.00 \\
\hline 17 & Guerrieri (4) & 38 & 21 & 68 & 6.94 \\
\hline 18 & Heintz (46) & 38 & 2 & 629 & 0.30 \\
\hline 19 & Jeong (47) & 25 & 5 & 130 & 0.88 \\
\hline 20 & Kanehira (48) & 25 & 11 & 54 & 3.86 \\
\hline 21 & Langer (49) & 40 & 2 & 661 & 0.30 \\
\hline 22 & Lebedyev (50) & 48 & 3 & 789 & 0.30 \\
\hline 23 & Lee-1 (51) & 73 & 14 & 368 & 0.91 \\
\hline 24 & Lee-2 (52) & 35 & 7 & 179 & 0.89 \\
\hline 25 & Lev-Chelouche (53) & 58 & 4 & 949 & 0.30 \\
\hline 26 & Levic (54) & 9 & 4 & 18 & 4.71 \\
\hline 27 & Lezoche (14) & 8 & 4 & 15 & 6.32 \\
\hline 28 & Lloyd (55) & 4 & 2 & 10 & 3.24 \\
\hline 29 & Marks (56) & 27 & 5 & 140 & 0.88 \\
\hline 30 & Maslekar (57) & 104 & 6 & 1685 & 0.31 \\
\hline 31 & Meng (58) & 30 & 2 & 501 & 0.30 \\
\hline 32 & Mentges (59) & 196 & 12 & 3156 & 0.31 \\
\hline 33 & Morino (60) & 214 & 13 & 3443 & 0.31 \\
\hline 34 & Nakagoe (28) & 150 & 9 & 2420 & 0.31 \\
\hline 35 & Neary $(61)$ & 38 & 2 & 629 & 0.30 \\
\hline 36 & Palma1 (62) & 46 & 3 & 757 & 0.30 \\
\hline 37 & Palma2 (63) & 8 & 3 & 20 & 2.43 \\
\hline 38 & Perez (64) & 5 & 2 & 10 & 4.32 \\
\hline 39 & Serra-Aracil (65) & 12 & 5 & 32 & 2.55 \\
\hline 40 & Steele (66) & 22 & 4 & 115 & 0.87 \\
\hline 41 & Stipa (13) & 4 & 3 & 6 & 14.20 \\
\hline 42 & Suzuki (67) & 28 & 2 & 469 & 0.30 \\
\hline 43 & Tsai (68) & 15 & 7 & 33 & 3.76 \\
\hline 44 & Turler (15) & 1 & 1 & 3 & 4.61 \\
\hline 45 & Verseveld (27) & 94 & 6 & 1525 & 0.31 \\
\hline 46 & Whitehouse (69) & 84 & 5 & 1365 & 0.31 \\
\hline 47 & Winde (70) & 23 & 4 & 120 & 0.87 \\
\hline 48 & Zacharakis (71) & 56 & 3 & 918 & 0.30 \\
\hline
\end{tabular}

Comparison of recurrence-free $O R$ in those studies which used neo+l-adjuvant treatment in more than $20 \%$ of the cases versus those which used in less than $20 \%$. We identified as the possible source of heterogeneity whether the use of neo+/-adjuvant treatment in more or less than $20 \%$ of
Table II. Effect sizes, confidence intervals and weights of each study.

\begin{tabular}{|c|c|c|c|c|c|}
\hline \multicolumn{2}{|c|}{ Study } & \multirow{2}{*}{$\begin{array}{c}\text { ES } \\
0.23\end{array}$} & \multicolumn{2}{|c|}{$\begin{array}{l}\text { [95\% Confidence } \\
\text { Interval] }\end{array}$} & \multirow{2}{*}{$\begin{array}{c}\% \\
\text { Weigh } \\
3.43\end{array}$} \\
\hline 1 & Allaix 2009 (30) & & 0.132 & 0.405 & \\
\hline 2 & Araki 2003 (31) & 0.02 & 0.004 & 0.072 & 1.98 \\
\hline 3 & Arezzo 2015 (32) & 0.08 & 0.01 & 0.588 & 1.27 \\
\hline 4 & Azimuddin 2000 & 0.10 & 0.022 & 0.406 & 1.91 \\
\hline 5 & Baatrup 2008 (34) & 0.22 & 0.145 & 0.34 & 3.65 \\
\hline 6 & Bačić 2014 (35) & 0.15 & 0.076 & 0.308 & 3.18 \\
\hline 7 & Bretagnol 2007 (36) & 0.18 & 0.086 & 0.386 & 3.08 \\
\hline 8 & Dafnis 2004 (38) & 0.20 & 0.044 & 0.913 & 1.81 \\
\hline 9 & De Graaf 2002 (39) & 0.09 & 0.037 & 0.197 & 2.93 \\
\hline 10 & DeMartines 2001 (40) & 0.09 & 0.012 & 0.704 & 1.25 \\
\hline 11 & Endreseth 2005 (41) & 0.15 & 0.035 & 0.682 & 1.85 \\
\hline 12 & Flexer 2013 (43) & 0.02 & 0.003 & 0.177 & 1.31 \\
\hline 13 & Floyd 2005 (44) & 0.08 & 0.029 & 0.226 & 2.59 \\
\hline 14 & Ganai 2006 (45) & 0.10 & 0.036 & 0.279 & 2.57 \\
\hline 15 & Guerrieri 2014 (4) & 0.04 & 0.028 & 0.071 & 3.57 \\
\hline 16 & Heintz 1998 (46) & 0.46 & 0.175 & 1.214 & 2.68 \\
\hline 17 & Jeong 2009 (72) & 0.04 & 0.005 & 0.295 & 1.3 \\
\hline 18 & Kanehira 2014 (48) & 0.04 & 0.018 & 0.092 & 2.96 \\
\hline 19 & Langer 2003(49) & 0.11 & 0.026 & 0.479 & 1.89 \\
\hline 20 & Lebedyev 2009 (50) & 0.04 & 0.006 & 0.322 & 1.29 \\
\hline 21 & Lee 2003 (51) & 0.09 & 0.038 & 0.203 & 2.93 \\
\hline 22 & Lee 2007 (52) & 0.09 & 0.028 & 0.296 & 2.31 \\
\hline 23 & Lev-Chelouche 2000 (53) & 0.16 & 0.056 & 0.46 & 2.53 \\
\hline 24 & Levic 2012 (54) & 0.50 & 0.031 & 8.065 & 0.79 \\
\hline 25 & Lezoche 2005 (14) & 0.05 & 0.021 & 0.129 & 2.81 \\
\hline 26 & Lloyd $2002(55)$ & 0.50 & 0.031 & 8.171 & 0.79 \\
\hline 27 & Marks 2003 (56) & 0.04 & 0.005 & 0.273 & 1.3 \\
\hline 28 & Maslekar 2007 (57) & 0.11 & 0.042 & 0.267 & 2.77 \\
\hline 29 & Meng 2004 (58) & 0.07 & 0.009 & 0.543 & 1.27 \\
\hline 30 & Mentges 1996 (59) & 0.03 & 0.01 & 0.1 & 2.36 \\
\hline 31 & Morino 2011 (60) & 0.24 & 0.152 & 0.393 & 3.57 \\
\hline 32 & Nakagoe 2002 (28) & 0.01 & 0.002 & 0.097 & 1.32 \\
\hline 33 & Neary $2003(61)$ & 0.50 & 0.03 & 8.297 & 0.78 \\
\hline 34 & Palma 2004 (62) & 0.05 & 0.006 & 0.337 & 1.29 \\
\hline 35 & Palma 2009 (63) & 0.06 & 0.015 & 0.261 & 1.94 \\
\hline 36 & Perez 2014 (64) & 0.21 & 0.098 & 0.451 & 3.06 \\
\hline 37 & Serra-Aracil 2008 (65) & 0.18 & 0.086 & 0.386 & 3.08 \\
\hline 38 & Steele $1996(66)$ & 0.10 & 0.022 & 0.406 & 1.91 \\
\hline 39 & Stipa 2012 (13) & 0.44 & 0.309 & 0.627 & 3.74 \\
\hline 40 & Suzuki 2005 (67) & 0.50 & 0.03 & 8.411 & 0.78 \\
\hline 41 & Turler 1997 (15) & 0.12 & 0.035 & 0.381 & 2.29 \\
\hline 42 & Verseveld 2015 (27) & 0.09 & 0.033 & 0.259 & 2.58 \\
\hline 43 & Whitehouse 2007 (69) & 0.24 & 0.109 & 0.508 & 3.05 \\
\hline 44 & Winde $1996(70)$ & 0.04 & 0.006 & 0.322 & 1.29 \\
\hline 45 & Zacharakis 2005 (71) & 0.40 & 0.176 & 0.908 & 2.96 \\
\hline & Pooled effect size & 0.115 & 0.087 & 0.152 & 100 \\
\hline
\end{tabular}

the cases for each study. In those studies where less than $20 \%$ of patients received neo+/-adjuvant treatment, the overall recurrence-free odds ratio was $8.0(95 \% \mathrm{CI}=6.1-10.3$, $p=0.000$ ) (Figure 5). A significant heterogeneity was detected as the Cochrane Q Statistic was $\mathrm{Q}=71.9$ on 35 d.f. 


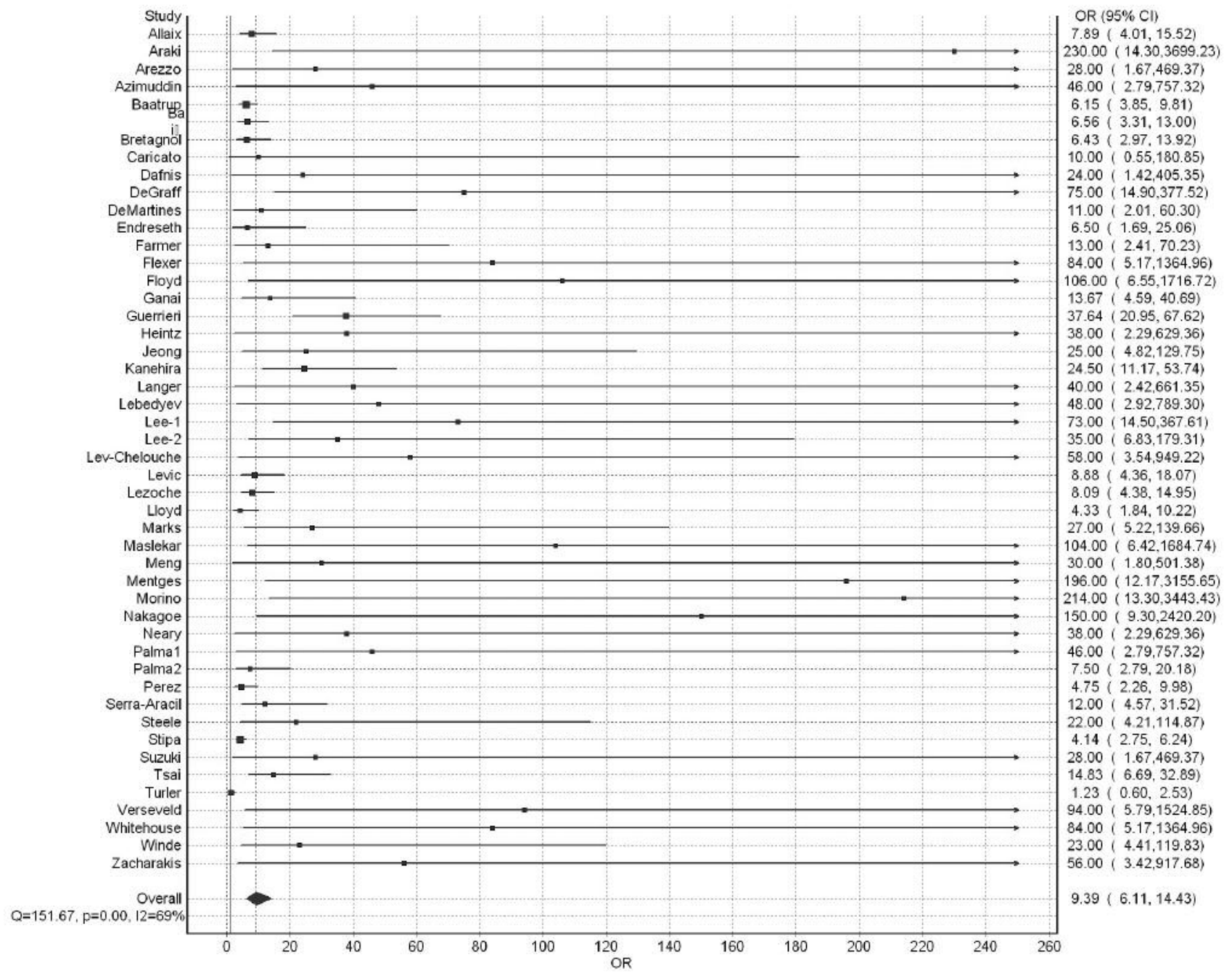

Figure 2. Survival forest plot.

$(p=0.000)$ and I-sq=51.3\%. On the other hand, those studies where more than $20 \%$ of patients received neo+/-adjuvant therapy had an overall recurrence-free OR of 11.3 (95\% CI=4.7-26.9; $p=0.000)$, with a highly significant heterogeneity ( $\mathrm{I}-\mathrm{sq}=89.1 \%$ and $p=0.000)$. This level of heterogeneity was attributed to a single study (Stipa et al., 2012 (13)) (Figure 6). By removing this study, (Figure 7) the heterogeneity reduced to a statistically non-significant level $(\mathrm{Q}=13.9$ on 7 d.f., $p=0.05$, I-sq=49\%). Excluding Stipa et al. 2012 , those studies with over $20 \%$ of patients receiving neo+/-adjuvant therapy had an overall recurrence-free OR of $14.0(95 \% \mathrm{CI}=8.1-24.0 ; p=0.000)$.

For studies including less than $20 \%$ of patients on neo+/adjuvant treatment, more benefit is seen with cohorts consisting of less than $10 \%$ pT3 tumours with a pooled effect size of $\mathrm{OR}=10 \quad(95 \% \mathrm{CI}=7.1-14.1 ; p=0.000)$ and low heterogeneity $(\mathrm{Q}=38$ on 22 d.f. $p=0.02)$. Nevertheless, in cohorts with more than $10 \%$ pT3 tumours, the pooled effect size was $\mathrm{OR}=5.6(95 \% \mathrm{CI}=4.1-7.7 ; p=0.000)$ with statistically non-significant heterogeneity $(\mathrm{Q}=20$ on 12 d.f. $p=0.07)$.

On multivariate meta-regression, the effect of the percentage of patients who received neo+/-adjuvant treatment on the likelihood of non-recurrence was statistically significant for studies with pT3 tumours in more than $10 \%$ of the cohort $(\mathrm{OR}=1.012 ; 95 \% \mathrm{CI}=1.001-1.022 ; p=0.03)$. In contrast, this effect was not statistically significant for those studies with less than $10 \%$ of pT3 cases $(\mathrm{OR}=0.996$; $95 \% \mathrm{CI}=0.98-1.01 ; p=0.50)$. 


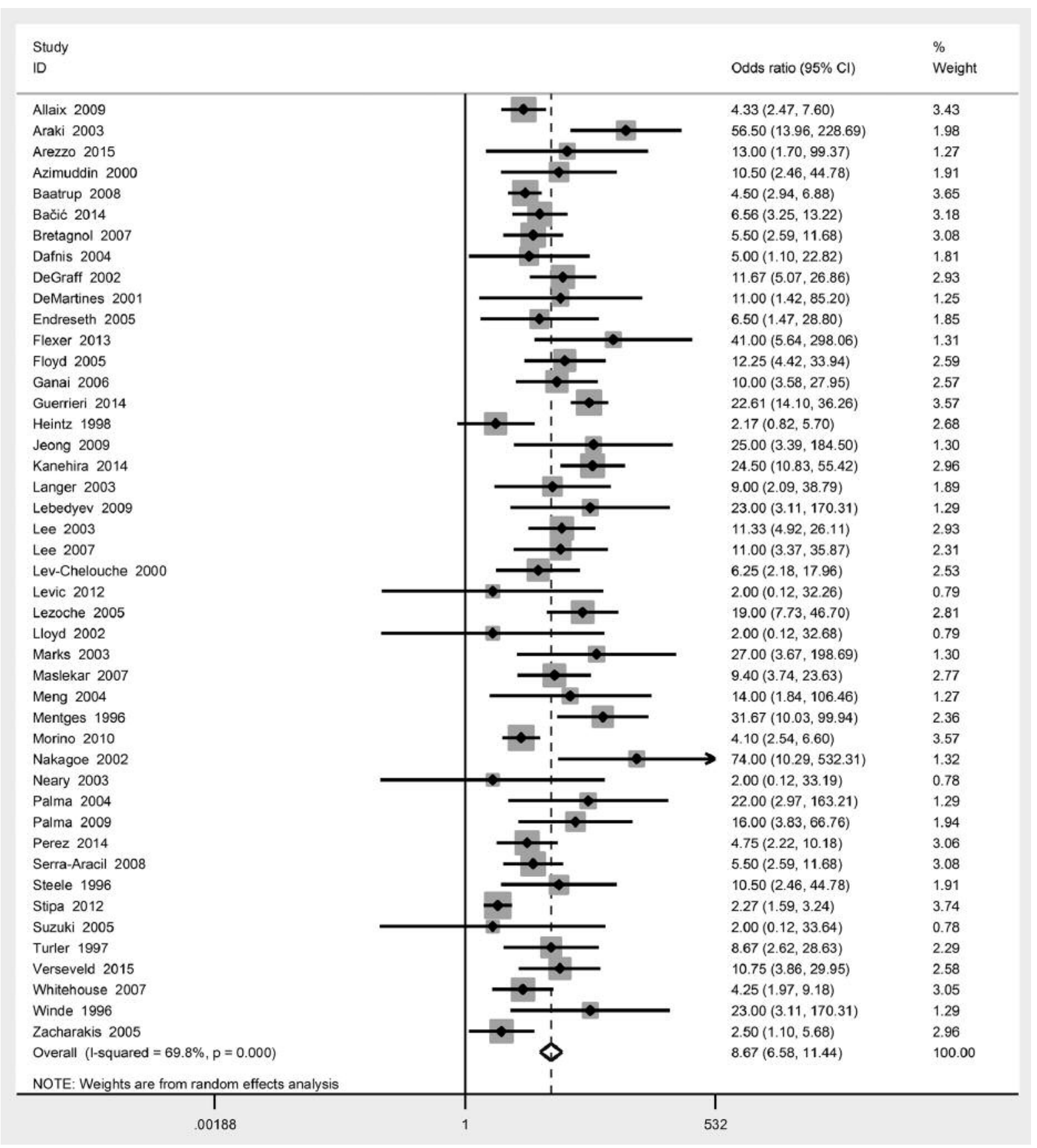

Figure 3. Odds Ratios for recurrence-free along with confidence intervals and weights.

Comparison of recurrence-free odds in those studies which used neo+/-adjuvant treatment in more than $20 \%$ of the cases and the cohorts consisted of less than $10 \%$ pT3 tumours versus those which consisted with more than $10 \%$ of pT3 tumours. Studies with more than $10 \%$ pT3 and more than $20 \%$ patients received neo+/-adjuvant therapy: The overall effect size was significant $(\mathrm{OR}=12.3 ; 95 \% \mathrm{CI}=3.4-44.5, p=0.000)$ although the highly significant heterogeneity that was detected required further inspection and stratification of the studies by effect size (Cochran $\mathrm{Q}=70$ on 4 d.f. $p=0.000$ and $\mathrm{I}-\mathrm{sq}=94 \%$ ) (Figure 8). The source of this heterogeneity was due to a single study, Stipa et al. 2012. Excluding this study (Figure 9), we found a completely homogeneous effect of neo+/-adjuvant treatment on recurrencefree survival with an OR of $20.2(95 \% \mathrm{CI}=13.8-29.6, p=0.000)$. The heterogeneity was non-significant $(\mathrm{Q}=2.18$ on 3 d.f., $p=0.54$ and $0 \%$ of the variation attributable to heterogeneity). 


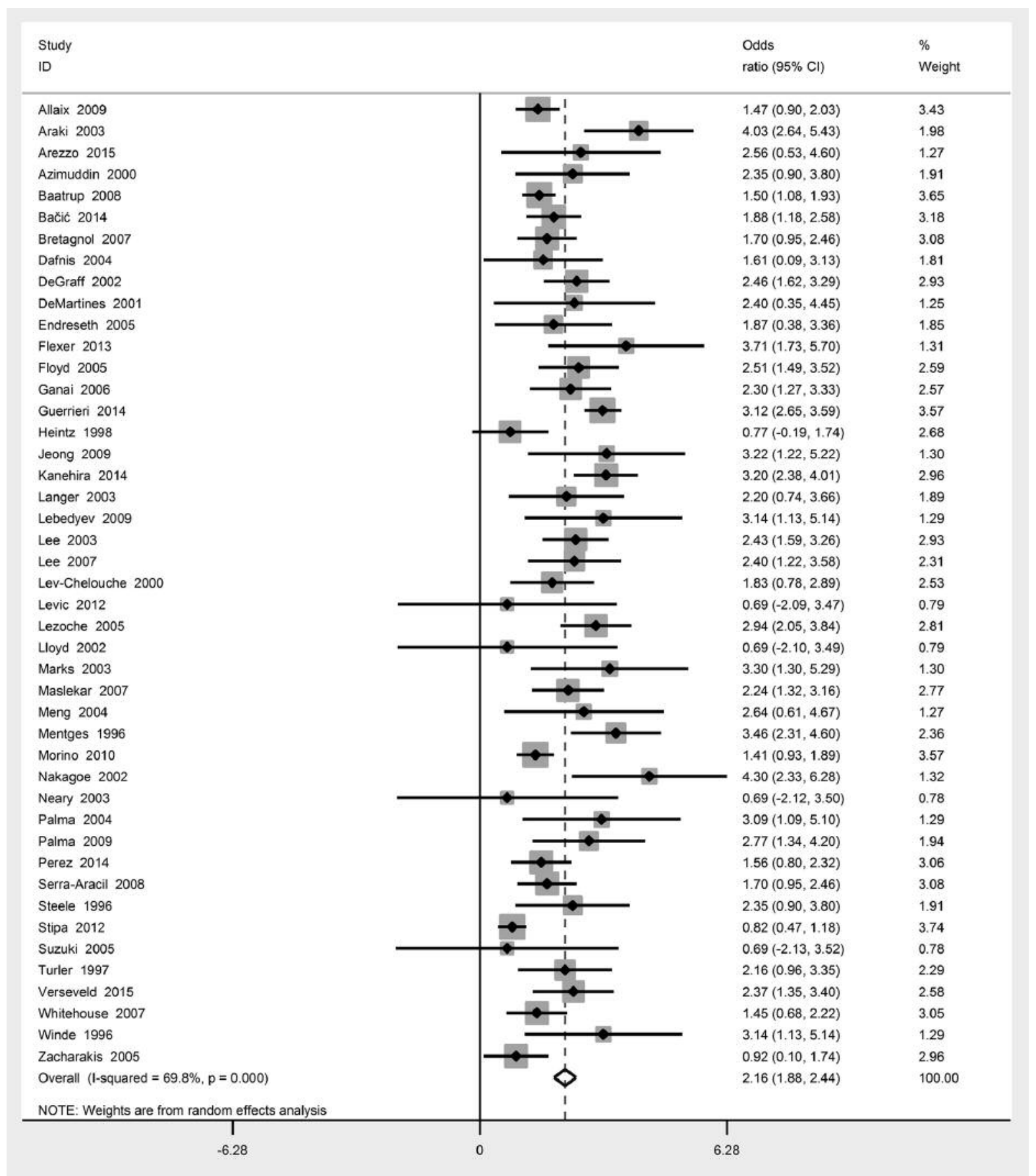

Figure 4. Log-OR for recurrence-free.

Studies with less than $10 \%$ pT3 AND more than $20 \%$ patients received neo+/-adjuvant therapy: The overall (pooled) effect size was statistically significant $(\mathrm{OR}=7.6$; $95 \% \mathrm{CI}-=3.8-44.8, p=0.000)$. No heterogeneity was present and the Cochran Q statistic was $3.4(p=0.33)$ with I-sq=12\% (Figure 10).

\section{Outcome: Cancer-Related Survival}

Overall effect sizes. Table I and Figure 2 show the confidence intervals for the overall (pooled) effect size for the 48 studies included in the final qualitative analysis, together with the assigned weights. The overall log-odds 


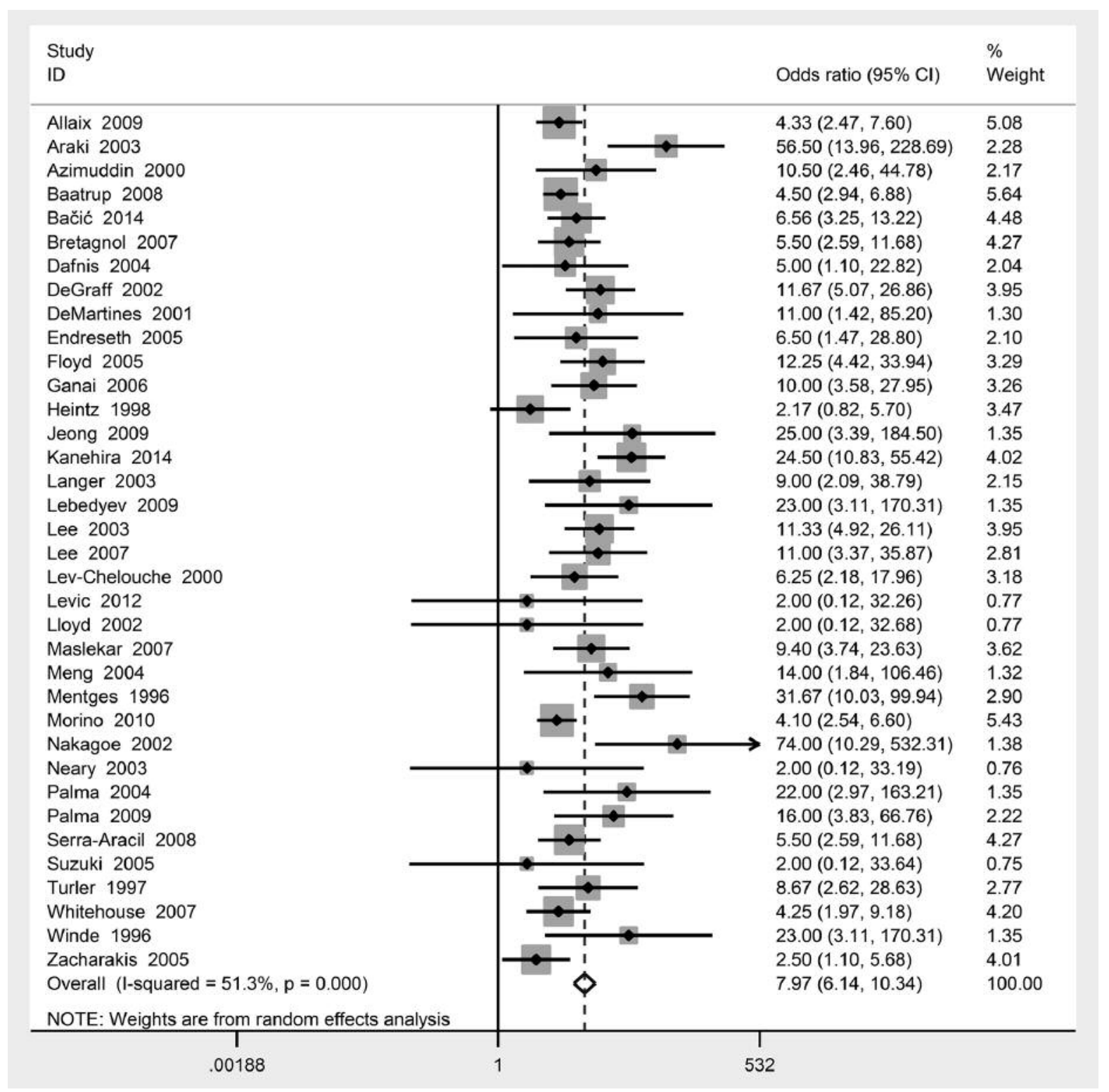

Figure 5. Recurrence-free OR for studies where less than $20 \%$ of patients that received neo+/-adjuvant treatment.

ratio for survival was $2.21(95 \% \mathrm{CI}=2.1-2.4, p=0.000)$. This translates into an odds ratio (OR) for survival of 9.39 (95\% CI=6.1-14.4). Cochran's $Q$ heterogeneity statistics variable was $\mathrm{Q}=151.7$ on 47 degrees of freedom (d.f.) $(p=0.000, \mathrm{I}-\mathrm{sq}=69 \%$,$) which was translated to a highly$ significant heterogeneity. We identified two possible sources of heterogeneity. Firstly, whether the study used neo+/adjuvant treatment in more or less than $35 \%$ of patients and secondly, whether the cohort of the study included more or less than $10 \%$ of pT3 stage specimens. A significant interaction between these two factors was also confirmed.
Comparison of survival OR in those studies which used neo+/-adjuvant treatment in more than $35 \%$ of the cases versus those which used in less than $35 \%$. We identified 34 studies which used neo+/-adjuvant treatment in less than $35 \%$ patients (Figure 11a). The overall (pooled) OR for survival on this group was 12.7 (95\% CI=9.6-16.6; $p=0.000)$ and the Cochran's $Q$ heterogeneity statistic was $Q=102.1$ on 33 d.f. $(p=0.000)$. In contrary, 13 studies reported that more than $35 \%$ of their cases received neo+/-adjuvant treatment (Figure 11b). On that group, survival OR was 8.1 (95\% CI $=6.7-9.8 ; p=0.000)$ and Cochran's Q Statistic 


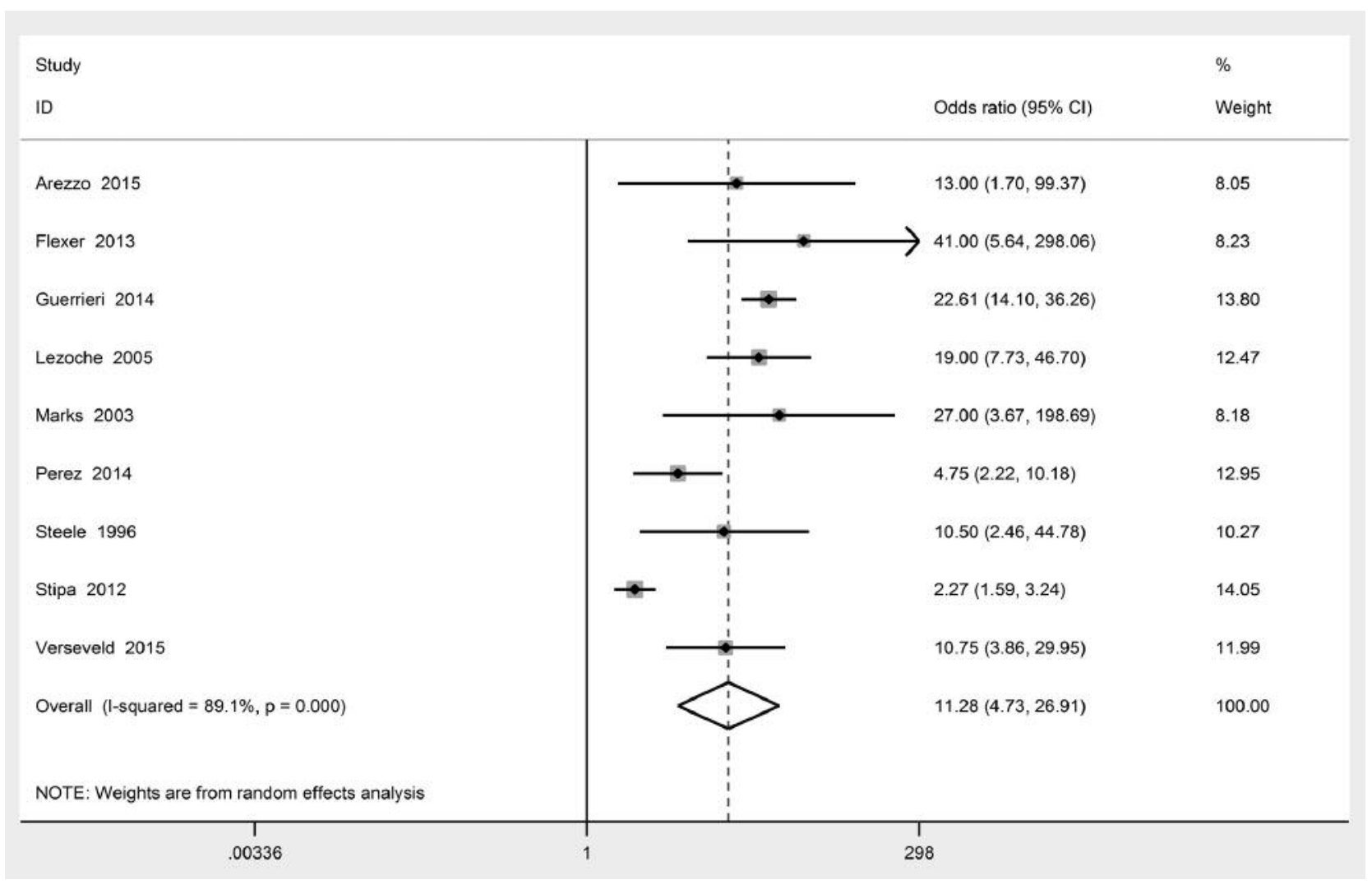

Figure 6. Recurrence-free OR for studies where more than $20 \%$ of patients that received neo+/-adjuvant treatment (including Stipa et al., 2012 (13)).

variable was $\mathrm{Q}=44.3$ on 12 d.f. $(p=0.000)$. This indicates that there is slightly better survival OR ratio for studies where $35 \%$ or more of the patients received neo+/-adjuvant treatment. The forest plots of these two groups are summarized in Figures $3 a$ and $3 b$.

On univariate meta-regression neither the high percent of neo-adjuvant $\mathrm{Rx}(\mathrm{Odds}=1.11 ; 95 \% \mathrm{CI}=0.50-2.5 ; p=0.78)$ nor the high percent of patients with T3-stage (Odds $=0.71 ; 95 \% \mathrm{CI}=$ $0.34-1.5 ; p=0.34$ ) significantly affect the odds of survival (Table III). Beyond the effects of the neo+/-adjuvant treatment and the percentage of pT3 stage cases, the OR of survival are 11.7-fold for those studies which offer neo+/-adjuvant treatment in more than $35 \%$ of the cases $(95 \% \mathrm{CI}=3.1-44 ; p=0.001)$.

Comparison of survival in those studies the cohorts of which had more than $10 \%$ pT3 and used neo+/-adjuvant treatment in more than $35 \%$ of the cases versus those which used in less than $35 \%$. In contrary to the univariate meta-regression, multivariate meta-regression analysis concluded to a statistically significant survival benefit from neo+/-adjuvant treatment in the presence of pT3 tumours $(p=0.001)$. More specifically, from the studies with cohorts that included more than $10 \%$ of pT3 specimens, those which offered neo+/- adjuvant treatment in more than $35 \%$ of the cases demonstrated higher OR of survival. To illustrate this significant interaction between pT3 stage and neo+/-adjuvant treatment, we stratified the studies into three groups according to the percentage of pT3-tumours. 17 studies with no pT3 specimens at all (Group 1), 12 studies with $1 \%$ to $10 \%$ pT3 specimens (Group 2) and the 19 studies with more than 10\% pT3 specimens (Group-3). On meta-regression analysis, the overall OR for survival was statistically nonsignificant for Group-1 and Group-2 $(p=0.11)$ but highly significant for Group-3 where the OR for survival was $\mathrm{OR}=3.9(95 \% \mathrm{CI}=1.3-12.0 ; p=0.02)$.

The overall pooled OR of survival for all these 19 studies was 8.1 (95\% CI=4.1-15.8) with a Cochran's Q heterogeneity variable of $\mathrm{Q}=94$ (18 d.f.). Of those 19 studies, 8 (42.1\%) studies used neo+/-adjuvant treatment in over $35 \%$ of the cases, where the overall pooled $\mathrm{OR}$ of survival was $20.4(95 \% \mathrm{CI}=8.2-50.7)$, and the Cochran's $\mathrm{Q}$ value was $\mathrm{Q}=21.4$ ( 10 d.f.). The only source of heterogeneity was found by Lezoche et al. (14). After removing this study, the remaining cohorts gave a homogeneous profile with odds of survival of 32.2 (95\% CI=16.3-63.5) and Cochran's $\mathrm{Q}$ Statistic of $\mathrm{Q}=8.4 p=0.21$. In the rest 11 studies neo+/- 


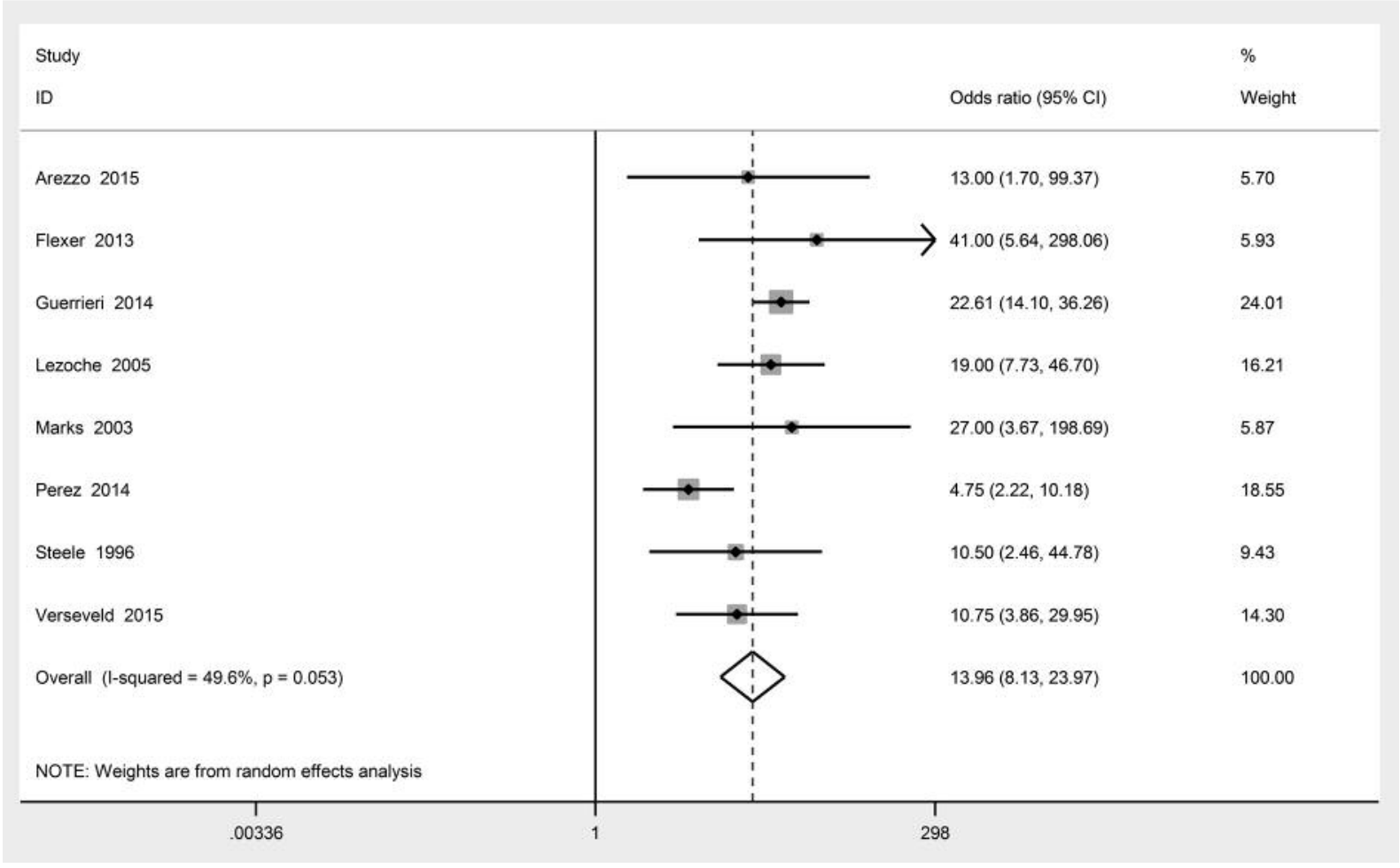

Figure 7. Recurrence-free OR for studies where more than $20 \%$ of patients that received neo+/- adjuvant treatment (excluding Stipa et al. 2012 (13)).

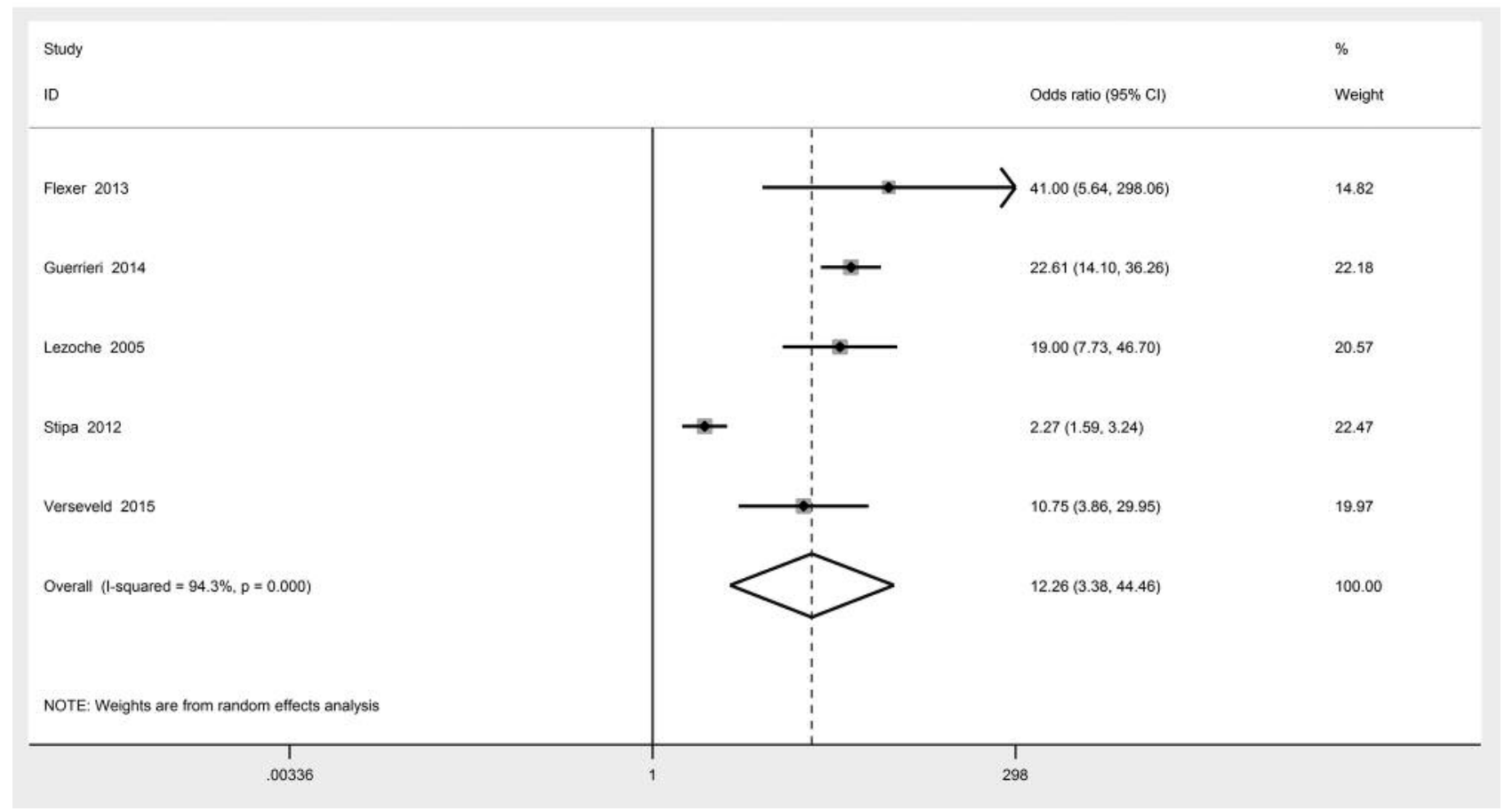

Figure 8. Overall effect size of recurrence-free OR for studies with more than $10 \%$ pT3 and more than $20 \%$ patients received neo+/-adjuvant therapy (including Stipa et al. $2012(13)$ ). 


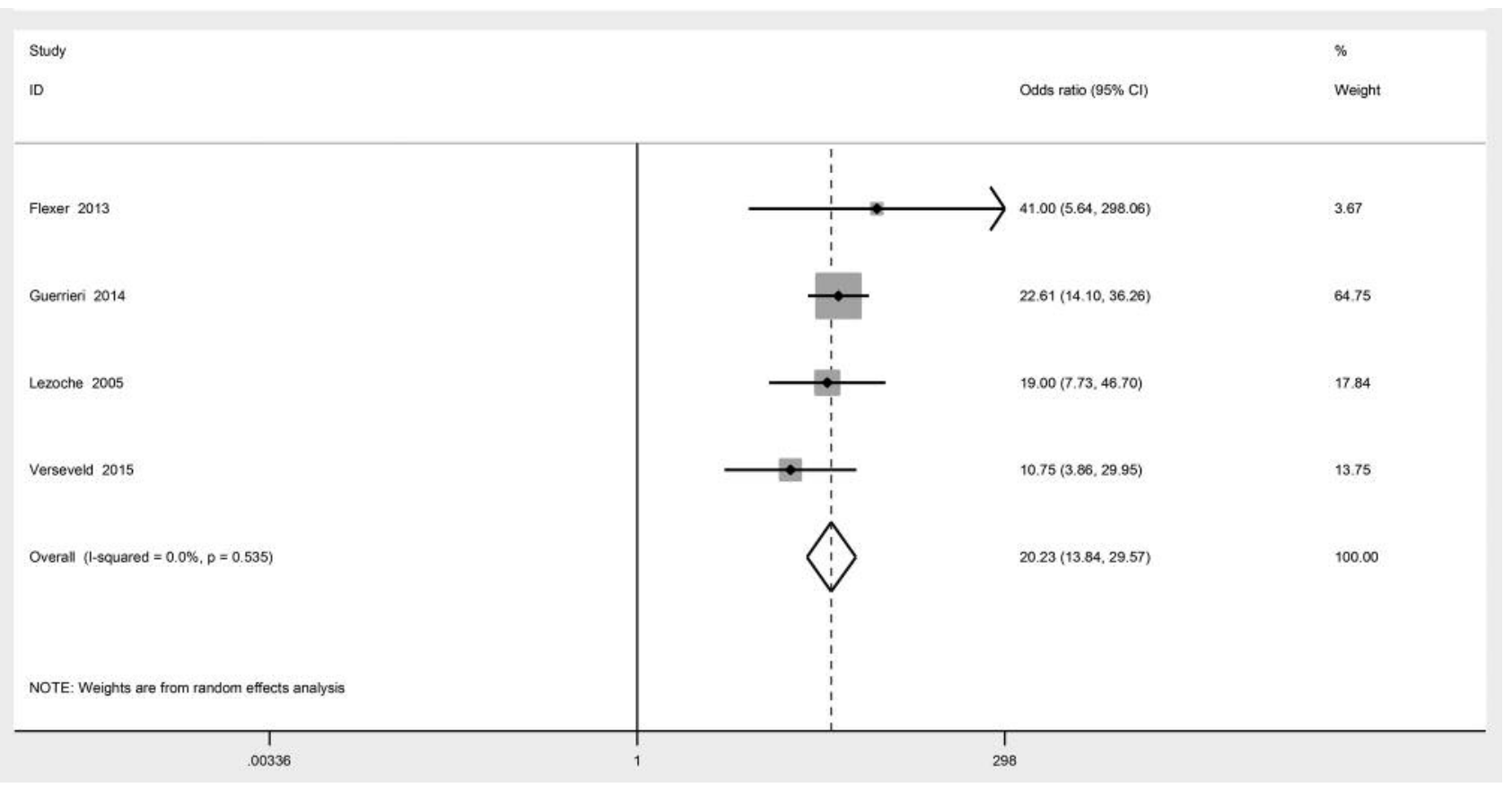

Figure 9. Overall effect size of recurrence-free OR for studies with more than 10\% pT3 and more than 20\% patients received neo+/-adjuvant therapy (excluding Stipa et al. 2012 (13)).

Table III. Results of the univariate meta-regressions for the overall log-odds of survival.

\begin{tabular}{|c|c|c|c|c|}
\hline & Log odds survival & & & $p$-Value \\
\hline Age & -0.01 & -0.08 & 0.07 & 0.85 \\
\hline Male patients & -0.36 & -0.86 & 0.14 & 0.15 \\
\hline Distance from anal verge $(\mathrm{cm})$ & 0.04 & -0.18 & 0.27 & 0.69 \\
\hline Tumor size & 0.00 & -0.02 & 0.01 & 0.60 \\
\hline Hospital stay (days) & -0.05 & -0.26 & 0.15 & 0.61 \\
\hline Follow up (months) & -0.01 & -0.03 & 0.01 & 0.33 \\
\hline pT1 cases & 0.003 & -0.01 & 0.02 & 0.62 \\
\hline pT2 cases & -0.01 & -0.03 & 0.01 & 0.25 \\
\hline pT3 cases & -0.03 & -0.07 & 0.01 & 0.18 \\
\hline pt4 cases & -0.10 & -0.35 & 0.15 & 0.43 \\
\hline Percentage pT3-stage above $10 \%$ & -0.34 & -1.1 & 0.38 & 0.34 \\
\hline $\mathrm{Neo+/-adjuvant} \mathrm{chemo} \mathrm{radiotherapy}$ & -0.001 & -0.01 & 0.01 & 0.84 \\
\hline Percentage of neo+/-adjuvant chemo radiotherapy $>35 \%$ & 0.11 & -0.68 & 0.90 & 0.78 \\
\hline Completion Surgery & -0.0044 & 0.10 & 1.86 & 0.07 \\
\hline
\end{tabular}

adjuvant treatment was used in less than $35 \%$ of the cases. The overall pooled odds of survival for those 11 studies was 5.4 (95\% CI=2.9-10.1) with a Cochran's heterogeneity statistic of $\mathrm{Q}=34.7$ (10 d.f.). Turler et al. (15) study was identified as the only source of heterogeneity and, after removing it, the rest gave a homogeneous profile with odds of survival of $6.4(95 \% \mathrm{CI}=4.1$ 10.1) and a Cochran's $\mathrm{Q}$ Statistic of $\mathrm{Q}=16.5 p=0.06$. For comparison, both forest plots (including the heterogeneous ones) are presented in Figure 12a and b.

\section{Discussion}

The introduction of local excision (either transanal (TAR), TEMS or TAMIS) for selected rectal cancers offered an alternative to patients who were either high risk for complications or refused to accept the option of a temporary or permanent stoma or the risk of sexual dysfunction. The limiting factor has been the higher risk of recurrence when surgery is the only modality (16). At the same time 


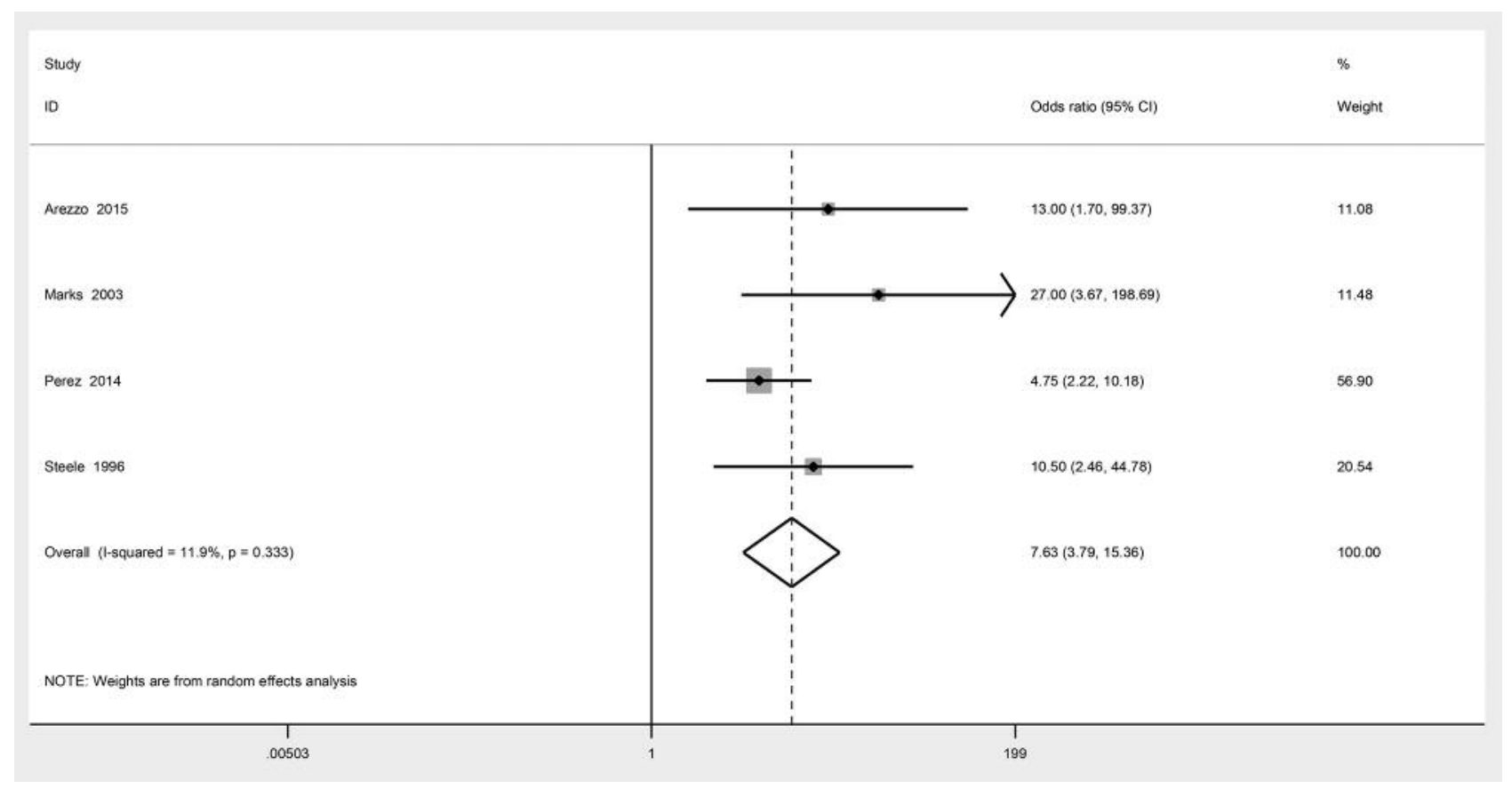

Figure 10. Overall effect size of recurrence-free OR for studies with less than 10\% pT3 and more than 20\% patients received neo+/-adjuvant therapy.

radiotherapy and chemotherapy are not indicated in the so far guidelines for early tumours $\mathrm{T} 1$ and $\mathrm{T} 2$, which are by default the primary target group for TEMS excision (17). Needless to say, the toxicity of radiotherapy and chemotherapy need to be taken into account and also communicated to the patient prior to any treatment decision, and that toxicity needs to be weighed against the risks of radical TME surgery (18). Last but not least, there has to be evidence of benefit of adjuvant/neo-adjuvant radiotherapy and/or chemotherapy. So far there is evidence for benefit of neoadjuvant radio-chemotherapy only for $\mathrm{T} 3$ tumours which had radical TME surgery and the benefit is primarily on local recurrence, and possibly on survival (19-21).

At present even though local excision, in the form of TAR, TEMS or TAMIS, is advised as one of the options to consider in the guidelines of ESMO, there is no guidance for adjuvant treatment in that setting (22). Our study aimed to investigate whether it is possible to isolate the effect of adjuvant radiotherapy in the context of TEMS for rectal cancer.

Several meta-analyses have been performed so far on the oncological outcomes of TEMS but none has reported on adjuvant radiotherapy. Wu et al. looked into T1 tumours and reported TEMS to have a similar 5 year survival between TEMS and TME with a lower mortality and complications rate for TEMS, which however carried a higher recurrence risk (12\% for TEMS $v s .0 .5 \%$ for TME) (23).
Sgourakis et al. (24) looked into both T1 and T2 tumours and concluded that TEMS had a higher local recurrence than TME but there was no difference in survival.

Kidane et al. (25) found that local resection of several techniques had higher local recurrence and lower overall survival but they attributed the findings to bias of the studies towards more adverse lower rectal tumours in the local resection group.

Lu et al. (6) also found that for T1 tumours there were no differences in survival and disease-free survival between TEMS and TME although there was a higher recurrence rate for TEMS.

Sajid et al. (26) examined T1 and T2 tumours and found similar survival and distal recurrence between TEMS and TME but TEMS had a higher local recurrence.

All the above referenced meta-analyses have similar results with regards to the oncological outcomes of TEMS for $\mathrm{T} 1$ or $\mathrm{T} 1+\mathrm{T} 2$ tumours. However, none of these report on the potential role of adjuvant radiotherapy, presumably because of inadequate existing data.

The possibility of radiotherapy as adjuvant treatment after TEMS is important because in cases of unfavourable histology (higher than expected stage, adverse histological factors) then the only other option is "completion surgery", i.e. the performance within a short time of radical TME as means of preventing local recurrence $(5,27,28)$. If it was shown that in those cases chemo-radiotherapy could be used instead, this would be an additional beneficial option for those patients. 


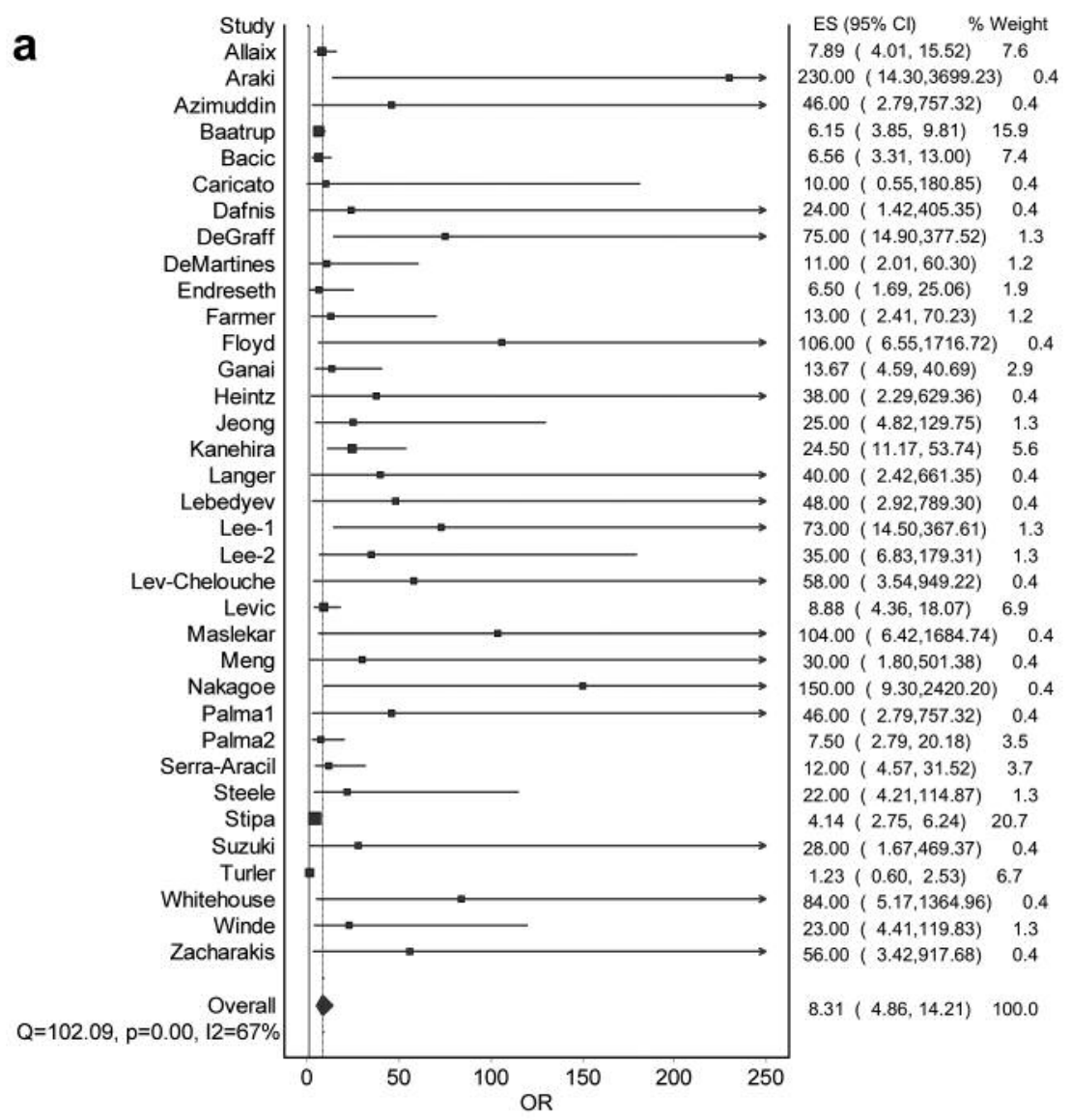

b

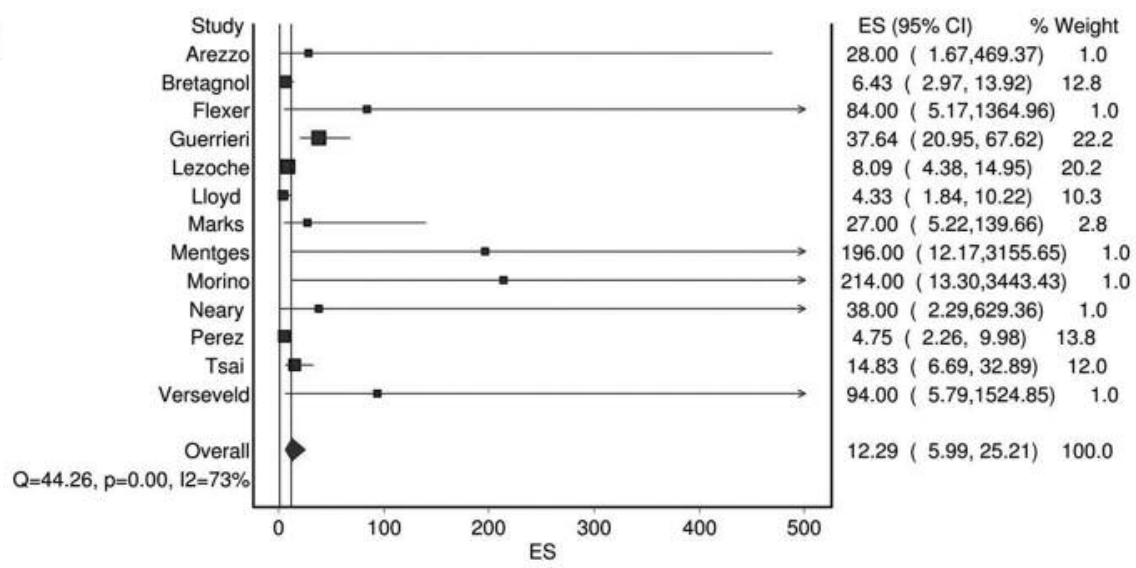

Figure 11. Forest plot for survival OR in studies with neo+/-adjuvant treatment a) in less than $35 \%$ of the cohorts, b) in $35 \%$ or more of the cohort cases.

Our systematic review aimed to investigate the effect of radiotherapy as adjuvant treatment to TEMS surgery and we believe has produced some interesting findings.

Our review was limited by the quality of the existing studies, few of which were randomised and there was a great degree of heterogeneity which we eliminated as much as possible with valid statistical methods.

On first analysis, there was no overall effect of radiotherapy on survival, however this changed when we analyzed studies according to the extent of adjuvant treatment. 

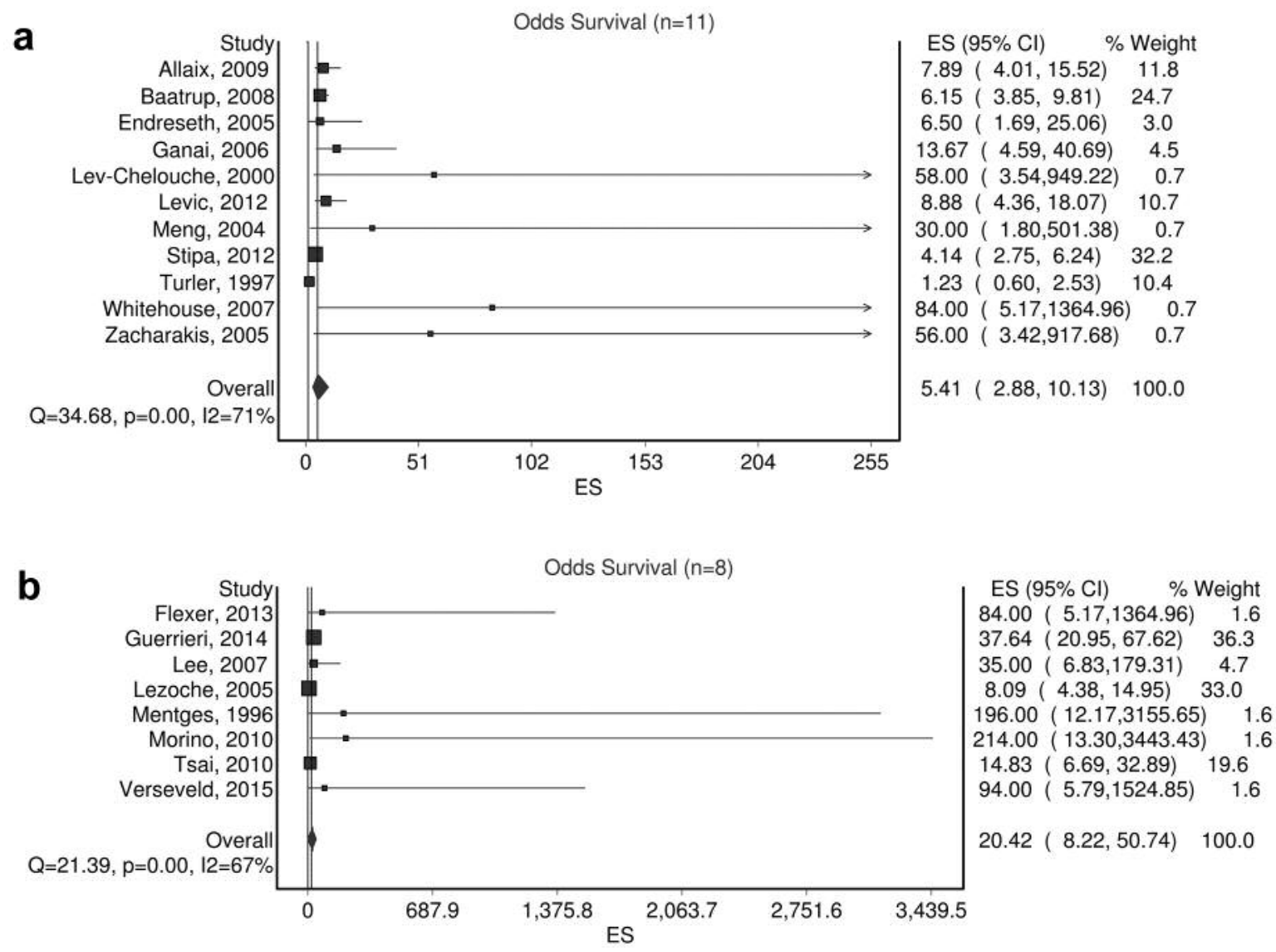

Figure 12. Forest plot for survival in studies having over $10 \%$ of pT3 stage tumours and a) $35 \%$ or less neo+/-adjuvant treatment or b) more than $35 \%$ in neoadjuvant $R x$.

There was a positive effect of radiotherapy regardless of stage if it was used in more than $35 \%$ of the patients. Interestingly this result persisted even when there was a higher percentage of $\mathrm{T} 3$ tumours in the study. T3 is a stage not normally indicated for TEMS and we can only hypothesize that those tumours were either discovered with a higher than expected histology post-resection or were treated that way because of fitness issues of the patients. It is interesting that survival is positively affected by radiotherapy uniformly, to our knowledge this is the first time that radiotherapy is shown to have a survival benefit on rectal cancer in this context. Of course, we appreciate that the methodology of a metaanalysis with inclusion of many non-randomized studies may carry a degree of bias and needs further testing with prospective randomised trials designed to address the specific issue.

A similar effect of radiotherapy was found on cancer recurrence. The consistency of the effect on both recurrence and survival decreases the possibility of a chance finding.
Are our findings capable of producing recommendations for change of strategy in treatment of rectal cancers by TEMS and radio-chemotherapy? No, not at this stage of research. There remains a plethora of unanswered questions with regards to tumor size, differentiation, and other adverse histological factors. There are also new directions of research into the effect of molecular factors in recurrence: we recently presented our finding that wild-type KRAS may be a favourable factor for decreased risk of local recurrence after TEMS surgery for rectal cancer (29). However, the effect is strong enough to motivate us to propose randomised controlled trials for further exploration.

\section{Conflicts of Interest}

None declared.

\section{Acknowledgements}

Funding was obtained from internal research funds and was part of $\mathrm{MD}$ (Res) thesis at King's College London. 


\section{References}

1 Heald RJ and Ryall RD: Recurrence and survival after total mesorectal excision for rectal cancer. Lancet (London, England) 1: 1479-1482, 1986.

2 How P, Shihab O, Tekkis P, Brown G, Quirke P, Heald R and Moran B: A systematic review of cancer related patient outcomes after anterior resection and abdominoperineal excision for rectal cancer in the total mesorectal excision era. Surg Oncol 20: e149-155, 2011.

3 Buess G, Kipfmüller K, Hack D, Grüssner R, Heintz A and Junginger T: Technique of transanal endoscopic microsurgery. Surg Endosc 2: 71-75, 1988.

4 Guerrieri M, Gesuita R, Ghiselli R, Lezoche G, Budassi A and Baldarelli M: Treatment of rectal cancer by transanal endoscopic microsurgery: experience with 425 patients. World J Gastroenterol 20: 9556-9563, 2014.

5 Papagrigoriadis S: Transanal endoscopic micro-surgery (TEMS) for the management of large or sessile rectal adenomas: a review of the technique and indications. Int Semin Surg Oncol 3: 13, 2006.

6 Lu J-Y, Lin G-L, Qiu H-Z, Xiao Y, Wu B and Zhou J-L: Comparison of transanal endoscopic microsurgery and total mesorectal excision in the treatment of $\mathrm{T} 1$ rectal cancer: a metaanalysis. PLoS One 10: e0141427, 2015.

7 Lezoche G, Baldarelli M, Guerrieri M, Mario, Paganini AM, De Sanctis A, Bartolacci S and Lezoche E: A prospective randomized study with a 5-year minimum follow-up evaluation of transanal endoscopic microsurgery versus laparoscopic total mesorectal excision after neoadjuvant therapy. Surg Endosc 22: 352-358, 2008.

8 Devereux L: Implementing early rectal cancer multidisciplinary teams in secondary care. Shar Learn Implement NICE Guid, 2012.

9 Lezoche G, Guerrieri M, Baldarelli M, Paganini AM, D'Ambrosio G, Campagnacci R, Bartolacci S and Lezoche E: Transanal endoscopic microsurgery for 135 patients with small nonadvanced low rectal cancer (iT1-iT2, iN0): short- and longterm results. Surg Endosc 25: 1222-1229, 2011.

10 Guerrieri M, Baldarelli M, Organetti L, Grillo Ruggeri F, Mantello G, Bartolacci S and Lezoche E: Transanal endoscopic microsurgery for the treatment of selected patients with distal rectal cancer: 15 years experience. Surg Endosc 22: 2030-2035, 2008.

11 Cochrane Collaboration: Cochrane Collaboration handbook. Strategies for addressing heterogeneity. 5.1. Cochrane Collaboration, 2016.

12 Doi S, Barendregt J, Khan S, Thalib L and Williams G: Advances in the meta-analysis of heterogeneous clinical trials I: The inverse variance heterogeneity model. Contemp Clin Trials 45: 130-138, 2015.

13 Stipa F, Giaccaglia V and Burza A: Management and outcome of local recurrence following transanal endoscopic microsurgery for rectal cancer. Dis Colon Rectum 55: 262-269, 2012.

14 Lezoche E, Guerrieri M, Paganini AM, Baldarelli M, De Sanctis A and Lezoche G: Long-term results in patients with T2-3 N0 distal rectal cancer undergoing radiotherapy before transanal endoscopic microsurgery. Br J Surg 92: 1546-1552, 2005.

15 Türler A, Schäfer $\mathrm{H}$ and Pichlmaier $\mathrm{H}$ : Role of transanal endoscopic microsurgery in the palliative treatment of rectal cancer. Scand J Gastroenterol 32: 58-61, 1997.
16 Bach SP, Hill J, Monson JRT, Simson JNL, Lane L, Merrie A, Warren B, Mortensen NJM and Association of Coloproctology of Great Britain and Ireland Transanal Endoscopic Microsurgery (TEM) Collaboration: A predictive model for local recurrence after transanal endoscopic microsurgery for rectal cancer. Br J Surg 96: 280-290, 2009.

17 Madoff RD: Chemoradiotherapy for rectal cancer - when, why, and how? N Engl J Med 351: 1790-1792, 2004.

18 King M, Tolan S, Giridharan S, McConkey C, Hartley A and Geh JI: Late toxicity after short course preoperative radiotherapy and total mesorectal excision for resectable rectal cancer. Clin Oncol (R Coll Radiol) 15: 233-236, 2003.

19 Wagman R, Minsky BD, Cohen AM, Guillem JG and Paty PP: Sphincter preservation in rectal cancer with preoperative radiation therapy and coloanal anastomosis: long term followup. Int J Radiat Oncol Biol Phys 42: 51-57, 1998.

20 Sauer R, Liersch T, Merkel S, Fietkau R, Hohenberger W, Hess C, Becker H, Raab H-R, Villanueva M-T, Witzigmann H, Wittekind C, Beissbarth $\mathrm{T}$ and Rödel C: Preoperative versus postoperative chemoradiotherapy for locally advanced rectal cancer: results of the German CAO/ARO/AIO-94 randomized phase III trial after a median follow-up of 11 years. J Clin Oncol 30: 1926-1933, 2012.

21 Swedish Rectal Cancer Trial, Cedermark B, Dahlberg M, Glimelius B, Påhlman L, Rutqvist LE and Wilking N: Improved survival with preoperative radiotherapy in resectable rectal cancer. N Engl J Med 336: 980-987, 1997.

22 Glynne-Jones R, Wyrwicz L, Tiret E, Brown G, Rödel C, Cervantes A, Arnold D and ESMO Guidelines Committee: Rectal cancer: ESMO Clinical Practice Guidelines for diagnosis, treatment and follow-up. Ann Oncol Off J Eur Soc Med Oncol 28: iv22-iv40, 2017.

$23 \mathrm{Wu}$ Y, Wu Y-Y, Li S, Zhu B-S, Zhao K, Yang X-D and Xing CG: TEM and conventional rectal surgery for $\mathrm{T} 1$ rectal cancer: a meta-analysis. Hepatogastroenterology 58: 364-368, 2011.

24 Sgourakis G, Lanitis S, Gockel I, Kontovounisios C, Karaliotas C, Tsiftsi K, Tsiamis A and Karaliotas CC: Transanal endoscopic microsurgery for $\mathrm{T} 1$ and $\mathrm{T} 2$ rectal cancers: a meta-analysis and meta-regression analysis of outcomes. Am Surg 77: 761-772, 2011.

25 Kidane B, Chadi SA, Kanters S, Colquhoun PH and Ott MC: Local resection compared with radical resection in the treatment of T1N0M0 rectal adenocarcinoma: a systematic review and meta-analysis. Dis Colon Rectum 58: 122-140, 2015.

26 Sajid MS, Farag S, Leung P, Sains P, Miles WFA and Baig MK: Systematic review and meta-analysis of published trials comparing the effectiveness of transanal endoscopic microsurgery and radical resection in the management of early rectal cancer. Colorectal Dis 16: 2-14, 2014.

27 Verseveld M, De Graaf EJR, Verhoef C, Van Meerten E, Punt CJA, De Hingh IHJT, Nagtegaal ID, Nuyttens JJME, Marijnen CAM and De Wilt JHW: Chemoradiation therapy for rectal cancer in the distal rectum followed by organ-sparing transanal endoscopic microsurgery (CARTS study). Br J Surg 102: 853$860,2015$.

28 Nakagoe T, Ishikawa H, Sawai T, Tsuji T, Tanaka K and Ayabe $\mathrm{H}$ : Surgical technique and outcome of gasless video endoscopic transanal rectal tumour excision. Br J Surg 89: 769-774, 2002. 
29 Sideris M, Moorhead J, Diaz-Cano S, Bjarnason I, Haji A and Papagrigoriadis S: KRAS Mutant Status, p16 and $\beta$-catenin Expression May Predict Local Recurrence in Patients Who Underwent Transanal Endoscopic Microsurgery (TEMS) for Stage I Rectal Cancer. Anticancer Res 36: 5315-5324, 2016.

30 Allaix ME, Arezzo A, Caldart M, Festa F and Morino M: Transanal endoscopic microsurgery for rectal neoplasms: Experience of 300 consecutive cases. Dis Colon Rectum 52: 1831-1836, 2009.

31 Araki Y, Isomoto $\mathrm{H}$ and Shirouzu K: Video-assisted gasless transanal endoscopic microsurgery: a review of 217 cases of rectal tumors over the past 10 years. Dig Surg 20: 48-52, 2003.

32 Arezzo A, Arolfo S, Allaix ME, Munoz F, Cassoni P, Monagheddu C, Ricardi U, Ciccone G and Morino M: Results of neoadjuvant short-course radiation therapy followed by transanal endoscopic microsurgery for $\mathrm{t} 1 \mathrm{t} \mathrm{t} 2 \mathrm{n} 0$ extraperitoneal rectal cancer. Int J Radiat Oncol Biol Phys 92: 299-306, 2015.

33 Azimuddin K, Riether RD, Stasik JJ, Rosen L, Khubchandani IT and Reed JF: Transanal endoscopic microsurgery for excision of rectal lesions: technique and initial results. Surg Laparosc Endosc Percutan Tech 10: 372-378, 2000.

34 Baatrup G, Breum B, Qvist N, Wille-Jørgensen P, Elbrønd H, Møller P and Hesselfeldt P: Transanal endoscopic microsurgery in 143 consecutive patients with rectal adenocarcinoma: results from a Danish multicenter study. Colorectal Dis 11: 270-275, 2009.

35 Bacic D, Durut I, Bukvic N and Cepic I: Transanal endoscopic microsurgery (TEM) - alternative or a method of choice in treating tumors of the rectum with appropriately selected patients? Coll Antropol 38: 1127-1130, 2014.

36 Bretagnol F, Merrie A, George B, Warren BF and Mortensen NJ: Local excision of rectal tumours by transanal endoscopic microsurgery. Br J Surg 94: 627-633, 2007.

37 Caricato M, Borzomati D, Ausania F, Tonini G, Rabitti C, Valeri S, Trodella L, Ripetti V and Coppola R: Complementary use of local excision and transanal endoscopic microsurgery for rectal cancer after neoadjuvant chemoradiation. Surg Endosc 20: 12031207, 2006.

38 Dafnis G, Påhlman L, Raab Y, Gustafsson U-M and Graf W: Transanal endoscopic microsurgery: clinical and functional results. Colorectal Dis 6: 336-342, 2004

39 de Graaf EJR, Doornebosch PG, Stassen LPS, Debets JMH, Tetteroo GWM and Hop WCJ: Transanal endoscopic microsurgery for rectal cancer. Eur J Cancer 38: 904-910, 2002.

40 Demartines $\mathrm{N}$, von Flüe MO and Harder FH: Transanal endoscopic microsurgical excision of rectal tumors: indications and results. World J Surg 25: 870-875, 2001.

41 Endreseth BH, Wibe A, Svinsås M, Mårvik R and Myrvold HE: Postoperative morbidity and recurrence after local excision of rectal adenomas and rectal cancer by transanal endoscopic microsurgery. Colorectal Dis 7: 133-137, 2005.

42 Farmer KC, Wale R, Winnett J, Cunningham I, Grossberg P and Polglase A: Transanal endoscopic microsurgery: the first 50 cases. ANZ J Surg 72: 854-856, 2002.

43 Flexer SM, Durham-Hall AC, Steward MA and Robinson JM: TEMS: results of a specialist centre. Surg Endosc 28: 18741878,2014

44 Floyd ND and Saclarides TJ: Transanal endoscopic microsurgical resection of pT1 rectal tumors. Dis Colon Rectum 49: 164-168, 2006.
45 Ganai S, Kanumuri P, Rao RS and Alexander AI: Local recurrence after transanal endoscopic microsurgery for rectal polyps and early cancers. Ann Surg Oncol 13: 547-556, 2006.

46 Heintz A, Mörschel M and Junginger T: Comparison of results after transanal endoscopic microsurgery and radical resection for T1 carcinoma of the rectum. Surg Endosc 12: 1145-1148, 1998.

47 Song JY, Kim JH, Cho YH, Kim CJ and Lee EJ: Treatment and Outcomes for Gangliogliomas: A Single-Center Review of 16 Patients. Brain Tumor Res Treat 2: 49, 2014.

48 Kanehira E, Tanida T, Kamei A, Nakagi M and Hideshima A: A single surgeon's experience with transanal endoscopic microsurgery over 20 years with 153 early cancer cases. Minim Invasive Ther Allied Technol 23: 5-9, 2014.

49 Langer C, Liersch T, Süss M, Siemer A, Markus P, Ghadimi BM, Füzesi L and Becker H: Surgical cure for early rectal carcinoma and large adenoma: transanal endoscopic microsurgery (using ultrasound or electrosurgery) compared to conventional local and radical resection. Int J Colorectal Dis 18: 222-229, 2003.

50 Lebedyev A, Tulchinsky H, Rabau M, Klausner JM, Krausz M and Duek SD: Long-term results of local excision for T1 rectal carcinoma: the experience of two colorectal units. Tech Coloproctol 13: 231-236, 2009.

51 Lee W, Lee D, Choi S and Chun H: Transanal endoscopic microsurgery and radical surgery for $\mathrm{T} 1$ and $\mathrm{T} 2$ rectal cancer. Surg Endosc 17: 1283-1287, 2003.

52 Lee WY, Lee W-S, Yun SH, Shin S-H and Chun H-K: Decision for salvage treatment after transanal endoscopic microsurgery. Surg Endosc 21: 975-979, 2007.

53 Lev-Chelouche D, Margel D, Goldman G and Rabau MJ: Transanal endoscopic microsurgery: experience with 75 rectal neoplasms. Dis Colon Rectum 43: 662-667, 2000.

54 Levic K, Bulut O, Hesselfeldt P and Bülow S: The outcome of rectal cancer after early salvage surgery following transanal endoscopic microsurgery seems promising. Dan Med J 59: A4507, 2012.

55 Lloyd GM, Sutton CD, Marshall LJ, Baragwanath P, Jameson JS and Scott ADN: Transanal endoscopic microsurgery - lessons from a single UK centre series. Colorectal Dis 4: 467-472, 2002.

56 Marks JH, Marchionni C and Marks GJ: Transanal endoscopic microsurgery in the treatment of select rectal cancers or tumors suspicious for cancer. Surg Endosc 17: 1114-1117, 2003.

57 Maslekar S, Pillinger SH and Monson JRT: Transanal endoscopic microsurgery for carcinoma of the rectum. Surg Endosc 21: 97-102, 2007.

58 Meng WCS, Lau PYY and Yip AWC: Treatment of early rectal tumours by transanal endoscopic microsurgery in Hong Kong: prospective study. Hong Kong Med J = Xianggang yi xue za zhi 10: 239-243, 2004.

59 Mentges B, Buess G, Schäfer D, Manncke K and Becker HD: Local therapy of rectal tumors. Dis Colon Rectum 39: 886-892, 1996.

60 Morino M, Allaix ME, Caldart M, Scozzari G and Arezzo A: Risk factors for recurrence after transanal endoscopic microsurgery for rectal malignant neoplasm. Surg Endosc 25: 3683-3690, 2011.

61 Neary P, Makin GB, White TJ, White E, Hartley J, MacDonald A, Lee PWR and Monson JRT: Transanal endoscopic microsurgery: a viable operative alternative in selected patients with rectal lesions. Ann Surg Oncol 10: 1106-1111, 2003. 
62 Palma P, Freudenberg S, Samel S and Post S: Transanal endoscopic microsurgery: indications and results after 100 cases. Colorectal Dis 6: 350-355, 2004.

63 Palma P, Horisberger K, Joos A, Rothenhoefer S, Willeke F and Post S: Local excision of early rectal cancer: is transanal endoscopic microsurgery an alternative to radical surgery? Rev Esp Enferm Dig 101: 172-178, 2009.

64 Perez RO, Habr-Gama A, São Julião GP, Proscurshim I, Coelho AQ, Figueiredo MN, Fernandez LM and Gama-Rodrigues $J$ : Transanal local excision for distal rectal cancer and incomplete response to neoadjuvant chemoradiation - does baseline staging matter? Dis Colon Rectum 57: 1253-1259, 2014.

65 Serra-Aracil X, Vallverdú H, Bombardó-Junca J, PericayPijaume C, Urgellés-Bosch J and Navarro-Soto S: Long-term follow-up of local rectal cancer surgery by transanal endoscopic microsurgery. World J Surg 32: 1162-1167, 2008.

66 Steele RJ, Hershman MJ, Mortensen NJ, Armitage NC and Scholefield JH: Transanal endoscopic microsurgery - initial experience from three centres in the United Kingdom. Br J Surg 83: 207-210, 1996.

67 Suzuki H, Furukawa K, Kan H, Tsuruta H, Matsumoto S, Akiya Y, Shinji $\mathrm{S}$ and Tajiri T: The role of transanal endoscopic microsurgery for rectal tumors. J Nippon Med Sch 72: 278-284, 2005 .

68 Tsai BM, Finne CO, Nordenstam JF, Christoforidis D, Madoff RD and Mellgrev A: Transanal endoscopic microsurgery resection of rectal tumors: Outcomes and recommendations. Dis Colon Rectum 53: 16-23, 2010.
69 Whitehouse PA, Armitage JN, Tilney HS and Simson JNL: Transanal endoscopic microsurgery: local recurrence rate following resection of rectal cancer. Colorectal Dis 10: 187-193, 2008.

70 Winde G, Nottberg H, Keller R, Schmid KW and Bünte H: Surgical cure for early rectal carcinomas (T1). Transanal endoscopic microsurgery $v s$. anterior resection. Dis Colon Rectum 39: 969-976, 1996.

71 Zacharakis E, Freilich S, Rekhraj S, Athanasiou T, Paraskeva P, Ziprin P and Darzi A: Transanal endoscopic microsurgery for rectal tumors: the St. Mary's experience. Am J Surg 194: 694698, 2007.

72 Jeong WK, Park JW, Choi HS, Chang HJ and Jeong SY: Transanal endoscopic microsurgery for rectal tumors: experience at Korea's National Cancer Center. Surg Endosc 23: 2575-2579, 2009.
Received January 12, 2018

Revised February 2, 2018

Accepted February 6, 2018 